\title{
Rh-Catalyzed Hydroformylation of 1,3-Butadiene and Pent-4-enal to Adipaldehyde in $\mathrm{CO}_{2}$-Expanded Media
}

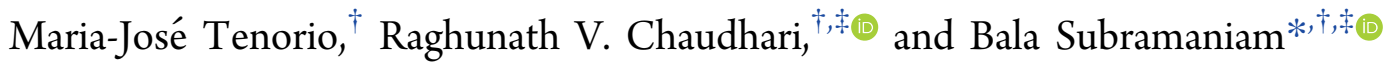 \\ ${ }^{\dagger}$ Center for Environmentally Beneficial Catalysis, University of Kansas, 1501 Wakarusa Drive, Lawrence, Kansas 66047, United \\ States \\ ${ }^{\ddagger}$ Department of Chemical and Petroleum Engineering, University of Kansas, 1530 W. 15th St., Lawrence, Kansas 66045, United \\ States
}

\section{Supporting Information}

\begin{abstract}
The homogeneous hydroformylation of pent-4-enal, the preferred aldehyde intermediate from 1,3-butadiene hydroformylation, was systematically investigated with $\mathrm{Rh}$ catalyst complexes in neat and $\mathrm{CO}_{2}$-expanded toluene media at $40-80{ }^{\circ} \mathrm{C}$, syngas partial pressures ranging from 5-50 bar, and different ligand/ $\mathrm{Rh}$ ratios. At similar operating conditions, the TOFs are generally greater with $\mathrm{Rh} / \mathrm{DIOP}$ relative to a $\mathrm{Rh} / \mathrm{TPP}$ catalyst. On both catalyst complexes, the chemoselectivity toward the dialdehydes
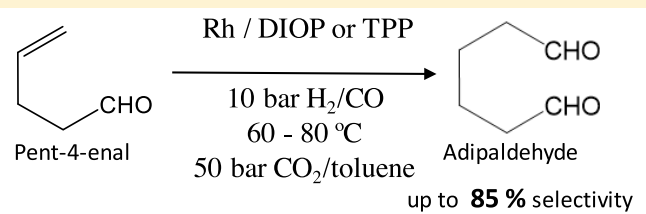

$\mathrm{CO}_{2}$-expanded media enhance adipaldehyde yield ranges from $75 \%-100 \%$, with the maximum adipaldehyde selectivity reaching approximately $75 \%(n / i \sim 3)$ at $60{ }^{\circ} \mathrm{C}, 10$ bar syngas, and molar DIOP/Rh ratio of 2.5. By using $\mathrm{CO}_{2}$-expanded toluene, the regioselectivity toward the adipaldehyde (desired product), and therefore its yield, is significantly enhanced. Interestingly, even with the simple $\mathrm{Rh} / \mathrm{TPP}$ catalyst complex, adipaldehyde selectivity of up to $85 \%(n / i \sim 5.6)$ is achieved at $60{ }^{\circ} \mathrm{C}, 10$ bar syngas, and 50 bar $\mathrm{CO}_{2}$. The beneficial effects of $\mathrm{CO}_{2}$-expanded media are attributed to the facile tunability of the $\mathrm{H}_{2} / \mathrm{CO}$ ratio in such a phase with a fixed syngas feed composition. This approach to accelerate pent-4-enal hydroformylation to form adipaldehyde could also help in overcoming equilibrium limitations typically associated with the catalytic isomerization of pent-3-enal (the dominant product from 1,3butadiene hydroformylation) to pent-4-enal (the preferred isomer).
\end{abstract}

\section{INTRODUCTION}

Adipic acid is an important large volume commodity product used as an intermediate for producing nylon-6,6. ${ }^{1,2}$ The current commercial process for adipic acid manufacture involves a two-step process: oxidation of cyclohexane to a mixture of cyclohexanol and cyclohexanone, which is oxidized to adipic acid using $\mathrm{HNO}_{3}$ and $\mathrm{H}_{2} \mathrm{SO}_{4}$ as reagents. ${ }^{3}$ The generation of large quantities of inorganic salts and the release of nitrous oxide emissions pose serious environmental concerns, providing a strong motivation to develop cleaner and atom-economical alternative routes for adipic acid. The hydroformylation of 1,3 butadiene ${ }^{4-6}$ provides such a route, in which one of the terminal olefin groups is first converted to the isomeric unsaturated monoaldehydes (pent-4-enal and pent-3enal) followed by hydroformylation of pent-4-enal to adipaldehyde (Scheme 1). Employing the $\mathrm{Rh}_{4}(\mathrm{CO})_{12} / \mathrm{DIOP}$ $[2,3$ - O - is o propylidene-2,3-dihydroxy-1,4-bis (diphenylphosphino)butane] complex for 1,3-butadiene hydroformylation, Ohgomori et al. ${ }^{7}$ reported $31 \%$ adipaldehyde selectivity at $80{ }^{\circ} \mathrm{C}$ and 20 bar syngas pressure. Smith et al. ${ }^{8}$ reported $50 \%$ adipaldehyde selectivity using the $\mathrm{Rh}$ $(\mathrm{CO})_{2}$ (acac)triptyphos (TTP) complex at $90{ }^{\circ} \mathrm{C}$ and under 40 bar syngas. Thus, the challenge is to develop such a process with much higher regioselectivity toward adipaldehyde at mild operating conditions.
It is known that the second hydroformylation step involving pent-4-enal (the terminal aldehyde) is faster relative to that of the internal aldehyde (pent-3-enal).,10 It is desirable to preferentially accelerate this step not only because it produces the desired dialdehyde (adipaldehyde) but also to shift the isomerization equilibrium toward pent-4-enal. Yet, there exist only a few published reports on the hydroformylation of pent4-enal. Rosendahl ${ }^{11}$ investigated the activity of two $\mathrm{Rh} /$ triptyphos-derived ligand complexes for hydroformylation of pent-4-enal at $90{ }^{\circ} \mathrm{C}$. Adipaldehyde selectivity was $94 \%$ with $5 \%$ valeraldehyde (pentanal, compound 6, Scheme 1) after 12 $\mathrm{h}$ at 20 bar syngas and $93.9 \%$ with $3.1 \%$ valeraldehyde after 24 $\mathrm{h}$ at 40 bar syngas. Mormul et al. ${ }^{12}$ tested several phosphine and biphosphite-based $\mathrm{Rh}$ complexes (including those containing DIOP and TPP ligands) for catalytic hydroformylation of pent-4-enal at $80{ }^{\circ} \mathrm{C}$ and 60 bar syngas during $2 \mathrm{~h}$ batch runs. With the $\mathrm{Rh} / \mathrm{TPP}$ catalyst complex, greater than $95 \%$ pent-4-enal conversion and $75 \%$ adipaldehyde selectivity are reported at a molar $\mathrm{TPP} / \mathrm{Rh}$ ratio of 15 . In

Special Issue: Chuck Eckert Festschrift

Received: September 16, 2019

Revised: October 23, 2019

Accepted: October 25, 2019

Published: October 25, 2019 
Scheme 1. 1,3-Butadiene Hydroformylation Pathways

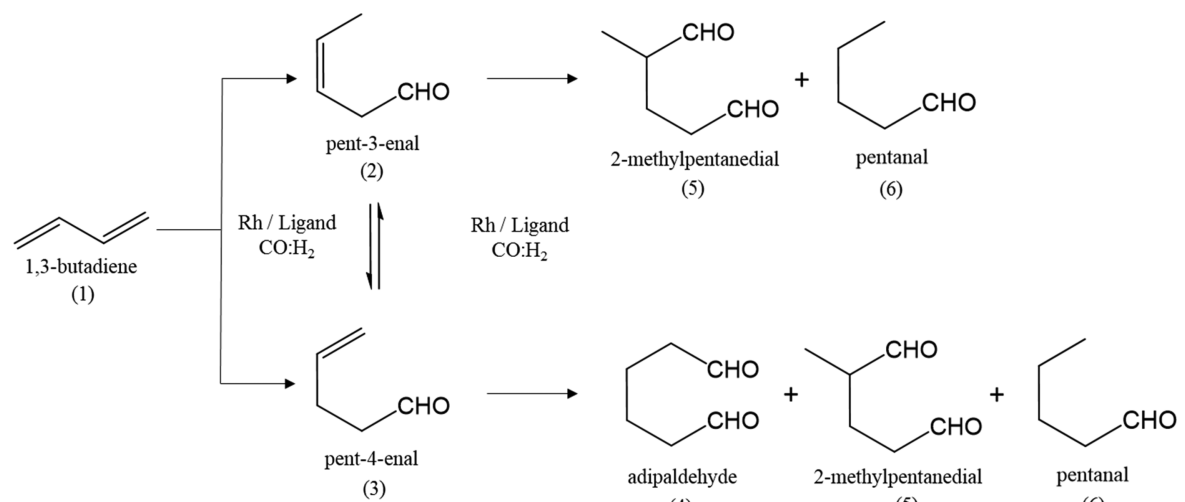

(3)

(5)

(6)

contrast, much lower pent-4-enal conversion (51\%) but $91 \%$ adipaldehyde selectivity are reported with the DIOP ligand using a lower ligand/Rh ratio of 1.5.

To enhance adipaldehyde yield, we investigate herein the use of gas-expanded liquids (GXLs), generated with nearcritical gases, as solvent media. At ambient temperatures, gases such as $\mathrm{CO}_{2}$ and light olefins are close to their critical temperatures such that, when compressed to few tens of bars, they dissolve in most conventional solvents creating a continuum of GXLs with pressure-tunable properties. ${ }^{13-15}$ Unlike conventional solvents, GXLs possess free volume that can accommodate permanent gases such as $\mathrm{O}_{2}, \mathrm{H}_{2}$, and $\mathrm{CO}$ in unusually high concentrations exceeding those governed by Henry's law. ${ }^{16-19}$ Further, the dissolved gas also enhances transport properties by increasing the intrinsic diffusivity of solutes in the GXL phase and decreasing the viscosity of the liquid phase. The unique properties and use of GXLs as reaction media have been reviewed elsewhere. ${ }^{13}$ The use of GXLs for 1,3-butadiene and pent-4-enal hydroformylation is motivated by our recent work showing that $\mathrm{CO}_{2}$-expanded liquids (CXLs) can give enhanced TOF and regioselectivity at mild pressure and temperature during 1-olefin hydroformylation with the Rh/TPP complex. ${ }^{20}$ With Rh complexes, higher $\mathrm{H}_{2}$ concentrations are needed for catalyst activation, and lower $\mathrm{CO}$ concentrations are generally required to avoid rate inhibition due to the formation of inactive carbonyl species. ${ }^{21}$ Because $\mathrm{CO}$ is generally more soluble than $\mathrm{H}_{2}$ in most conventional solvents, ${ }^{22-24}$ the resulting $\mathrm{H}_{2} / \mathrm{CO}$ ratio in the liquid phase is less than that in the feed syngas. In contrast, when dense $\mathrm{CO}_{2}$ is added to either 1-octene or nonanal at a fixed syngas partial pressure, $\mathrm{H}_{2}$ becomes more soluble than $\mathrm{CO}$ in the resulting CXLphase. ${ }^{18}$ This unique ability to pressure-tune the $\mathrm{H}_{2} / \mathrm{CO}$ ratio in CXL media with a syngas feed with a fixed $\mathrm{H}_{2} / \mathrm{CO}$ ratio provides an additional lever (along with ligand design) to enhance TOF and regioselectivity at relatively mild conditions. ${ }^{25}$ In this work, we investigate the hydroformylation of 1,3-butadiene and pent-4enal in CXLs with Rh catalyst complexes, aimed at enhancing the yield of the desired adipaldehyde.

\section{EXPERIMENTAL SECTION}

Materials. A rhodium catalyst precursor, acetylacetonatodicarbonyl rhodium(I) $\left[\mathrm{Rh}(\mathrm{acac})(\mathrm{CO})_{2}\right]$ (98\% purity), and a triphenylphosphine (TPP, ReagentPlus grade) ligand were procured from Sigma-Aldrich and used as received. The second ligand, (+)-2,3-O-isopropylidene-2,3-dihydroxy-1,4-bis(diphenylphosphino)butane or (+)-DIOP (98\% purity) and pent-4-enal (97\% purity) were purchased from Alfa Aesar. A solution of $20 \mathrm{wt} \%$ 1,3-butadiene in toluene, toluene (anhydrous, 98\% purity), and decane (ReagentPlus grade) were acquired from Aldrich Chemical Co. Carbon dioxide $\left(\mathrm{CO}_{2}, 99.999 \%\right)$ and syngas (99.99\% purity; molar $\mathrm{H}_{2} / \mathrm{CO}$ ratio 1:1) were purchased from Matheson.

Apparatus and Procedures. Volumetric Expansion Studies. For measuring the volumetric expansion of a typical hydroformylation reaction mixture of known composition by $\mathrm{CO}_{2}$, a Jerguson view cell (50 mL, Clark Reliance Co.) was used to determine the operating conditions $(P, T$, substrate volume) for performing homogeneous hydroformylation (Figure 1). The apparatus and operating procedures are

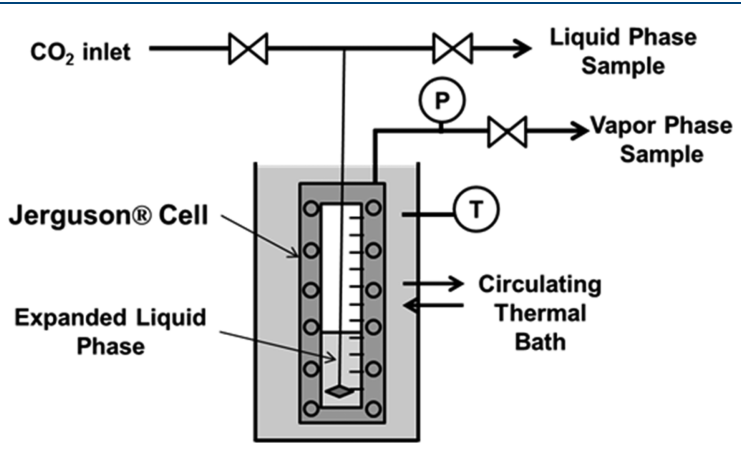

Figure 1. Schematic of apparatus to measure volumetric expansion of representative 1,3-butadiene hydroformylation mixtures by pressurized $\mathrm{CO}_{2}$.

described elsewhere. ${ }^{26}$ An air-actuated magnet-driven stirring bar was added to intensify gas-liquid mixing and eliminate mass transfer limitations. In a typical run, a known amount of organic liquid ( $9 \mathrm{~mL}$ of toluene $+0.5 \mathrm{~mL}$ of decane) containing reactants $(30 \mathrm{mmol}$ of 1,3-butadiene or $5 \mathrm{mmol}$ of pent-4-enal) and catalyst $\left[\mathrm{Rh}(\mathrm{CO})_{2}(\mathrm{acac})+\mathrm{DIOP}\right.$ or TPP $]$ at various compositions was placed in the view cell housed in a circulating water bath. The cell contents were thus brought to the desired temperature. Known amounts of carbon dioxide were gradually introduced through a syringe pump. Following equilibration $(20 \mathrm{~min})$ at each pressure at a fixed temperature, the isothermal expansion of the liquid phase by carbon dioxide was recorded in terms of the relative increase in the liquid volume from the initial state to the final state.

$$
\frac{V}{V_{0}}=\frac{V(T, P)}{V_{0}\left(T, P^{*}\right)}
$$


where $V_{0}\left(T, P^{*}\right)$ is the initial volume of the $\mathrm{CO}_{2}$-free liquid phase at ambient $P^{*}$ and bath temperature $T$, and $V(T, P)$ is the equilibrated volume of $\mathrm{CO}_{2}$-expanded phase at the final state $\left(\mathrm{CO}_{2}\right.$ pressure, $P$, and bath temperature, $\left.T\right)$.

The $\mathrm{CO}_{2}$-expanded volume was also predicted using the Peng-Robinson equation of state (PR-EOS). ${ }^{27}$ An ASPEN PLUS process simulator was employed to perform the PR-EOS model calculations. Binary interaction parameters were obtained from the ASPEN PLUS database at the required conditions (compositions of the binary system, temperatures, and pressures).

Hydroformylation Experiments. The hydroformylation experiments were carried out in a stirred batch reactor as described elsewhere. ${ }^{26}$ A schematic of the experimental setup is shown in Figure 2. Hydroformylation of 1,3-butadiene and

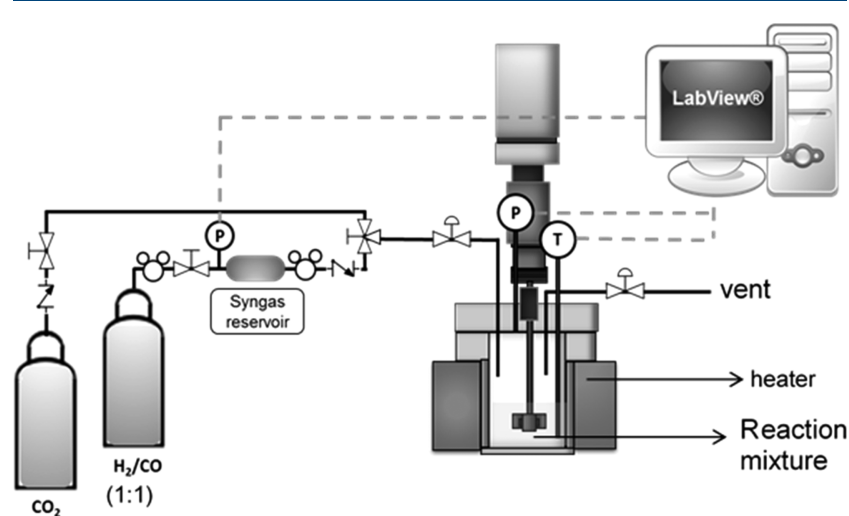

Figure 2. Schematic of reactor unit for investigating homogeneous hydroformylation in neat and $\mathrm{CO}_{2}$-expanded toluene

pent-4-enal was investigated using a $50 \mathrm{~mL}$ high-pressure Parr reactor. Mixing is provided by a magnetic stirrer with a maximum agitation rate of $1700 \mathrm{rpm}$. Pressure and temperature in the reactor were monitored by a Labview data acquisition system and controlled with a Parr 4840 controller. Syngas was introduced from a gas reservoir equipped with a pressure regulator and a pressure transducer. The pressure regulator, located at the exit of the reservoir, is used to admit syngas and maintain a constant total pressure in the reactor. The pressure transducer monitors the total pressure in the reservoir which drops due to syngas consumption by reaction.

The investigations were performed using toluene as a solvent at constant syngas (molar $\mathrm{CO} / \mathrm{H}_{2}=1$ ) partial pressures ranging from 5 to 50 bar and at temperatures between 60 and $80{ }^{\circ} \mathrm{C}$. The catalyst complex was composed of $\mathrm{Rh}$ $(\mathrm{CO})_{2}(\mathrm{acac})$ as the rhodium source and either DIOP or TPP as the ligand. The stirrer speed was maintained at 1000 rpm to eliminate gas-liquid mass transfer limitations. ${ }^{28}$

In a typical run, $10 \mathrm{~mL}$ of a solution containing either 1,3butadiene or pent-4-enal dissolved in toluene is charged into the Parr reactor. The catalyst complex is dissolved in toluene, and $0.5 \mathrm{~mL}$ of decane is added as the internal standard to this mixture. The contents are heated to the desired temperature with gentle stirring. In experiments performed in $\mathrm{CO}_{2}-$ expanded media, the reactor is pressurized with $\mathrm{CO}_{2}$ to a predetermined value to cause volumetric expansion. After allowing $20 \mathrm{~min}$ for the system to equilibrate, the reactor is pressurized to a predetermined value with premixed syngas from an external gas reservoir. The stirrer speed is then increased to $1000 \mathrm{rpm}$ to start the reaction. To operate at constant syngas pressure, the gas phase is continuously replenished with syngas from the external reservoir containing syngas (molar $\mathrm{CO} / \mathrm{H}_{2}=1$ ). The initial 1,3-butadiene partial pressure in the gas phase at $80{ }^{\circ} \mathrm{C}$ (prior to the commencement of hydroformylation) is $\sim 2$ bar.

The substrate conversion, chemoselectivity, regioselectivity, and turnover frequency (TOF) are defined as follows:

$$
\text { Conversion }(\%)=\frac{(\text { moles olefin })_{i}-(\text { moles olefin })_{f}}{(\text { moles olefin })_{i}} \times 100
$$

The chemoselectivity is defined as the number of moles of aldehydes formed relative to the number of moles of substrate reacted.

$$
\text { Chemoselectivity }(\%)=\frac{\text { moles of dialdehydes formed }}{\text { moles of olefin converted }} \times 100
$$

The regioselectivity $(n / i)$ is estimated as the molar ratio of the linear to branched aldehydes in the product.

$$
\text { Regioselectivity }(n / i)=\frac{\text { moles linear dialdehyde }}{\text { moles branched dialdehyde }}
$$

The TOF is estimated from the number of moles of $\mathrm{CO}$ or $\mathrm{H}_{2}$ consumed corresponding to $20 \%$ syngas conversion, estimated from the pressure drop in the external syngas reservoir at the end of a run.

$$
\text { TOF }\left(\mathrm{h}^{-1}\right)=\frac{\text { Moles of syngas consumed corresponding to } 20 \% \text { conversion }}{2 \times \text { moles of } \mathrm{Rh} \times \text { time }}
$$

Analytical. Gas chromatographic analysis was performed on an Agilent Technologies GC System equipped with a $30 \mathrm{~m}$ HP-5 [(5\%-phenyl)-methylpolysiloxane] nonpolar capillary column and flame ionization detector (FID). The flow rate was kept at $5 \mathrm{~mL} / \mathrm{min}$. The column temperature was initially held at $35{ }^{\circ} \mathrm{C}$ for $5 \mathrm{~min}$, then ramped at $5{ }^{\circ} \mathrm{C} / \mathrm{min}$ to $100{ }^{\circ} \mathrm{C}$, followed by an immediate temperature ramp of $10^{\circ} \mathrm{C} / \mathrm{min}$ to $225^{\circ} \mathrm{C}$, and held at this temperature for $7 \mathrm{~min}$.

Typical retention times $(\mathrm{min})$ are as follows: 1,3-butadiene (3.3 $\mathrm{min})$, pent-4-enal (5.2 $\mathrm{min})$, pentanal ( $5.7 \mathrm{~min})$, pent-3enal (5.8 $\mathrm{min})$, pent-2-enal $(7.2 \mathrm{~min})$, adipaldehyde $(14.5$ $\mathrm{min})$, 2-methylpentanedial (12.7 $\mathrm{min})$, and decane (14.2 $\mathrm{min})$. Peak assignments were confirmed with samples of commercially available or independently synthesized compounds, and in some cases, GC/MS analysis was carried out to identify specific compound. A typical GC/FID trace is given in the Supporting Information (Figure S1).

\section{RESULTS AND DISCUSSION}

Volumetric Expansion Studies. The volumetric expansions of typical 1,3-butadiene hydroformylation and pent-4enal hydroformylation reaction mixtures by $\mathrm{CO}_{2}$ were measured to establish the range of operating conditions $(P$, $T$, substrate volume) suitable for performing homogeneous hydroformylation. The view cell used to measure the volumetric expansion and its operation are described elsewhere. Figure 3 shows the relative volume expansion of a binary mixtures of 1,3-butadiene and toluene (10 wt \% 1,3butadiene $+90 \mathrm{wt} \%$ toluene) upon $\mathrm{CO}_{2}$ pressurization up to 60 bar at temperatures between 30 and $70{ }^{\circ} \mathrm{C}$. As expected, the volumetric expansion was greater and more sensitive to pressure at the lower temperature $\left(30^{\circ} \mathrm{C}\right)$ as compared to 


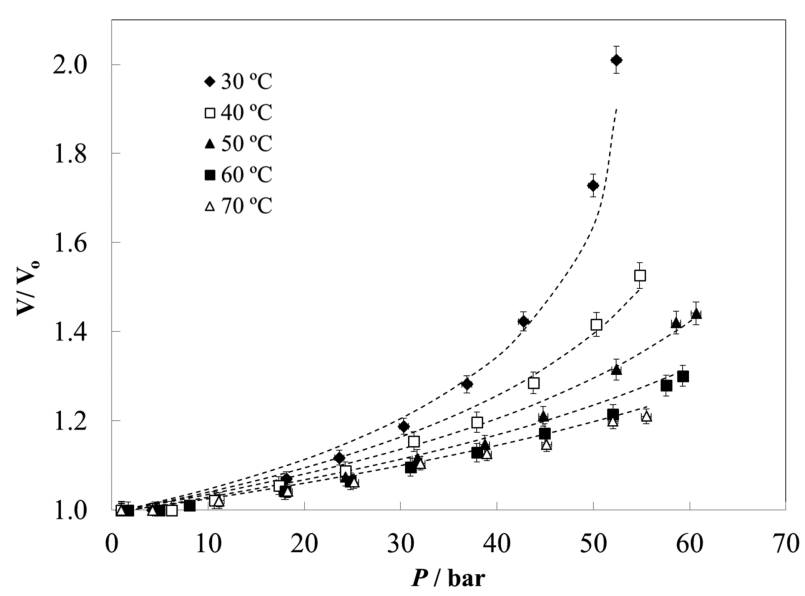

Figure 3. Volumetric expansion of $10 \mathrm{wt} \%$ 1,3-butadiene $+90 \mathrm{wt} \%$ toluene $(10 \mathrm{~mL})$ mixture by $\mathrm{CO}_{2}$. Dashed lines correspond to simulations by ASPEN PLUS software.

the higher temperatures $\left(50,60\right.$, or $\left.70{ }^{\circ} \mathrm{C}\right)$. At a given pressure, the $\mathrm{CO}_{2}$ density and therefore its solubility in the CXL phase decrease with an increase in temperature.

Figure 4 shows the volumetric expansion of two hydroformylation mixtures containing the dissolved catalyst complex.

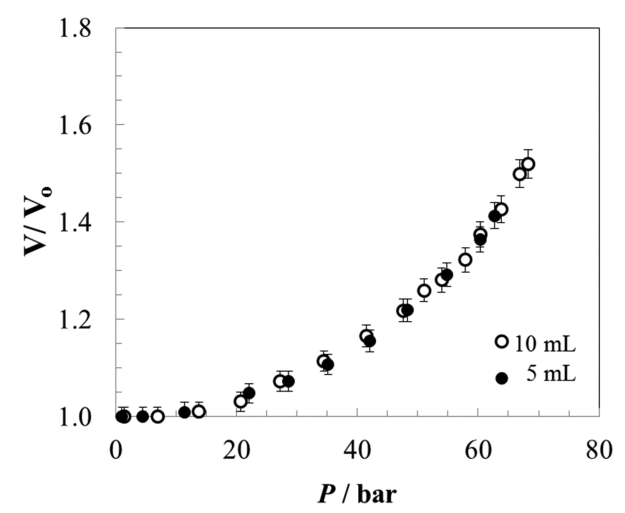

Figure 4. Volumetric expansion of 1,3-butadiene hydroformylation reaction mixtures (20 wt \% 1,3-butadiene $+80 \mathrm{wt} \%$ toluene + DIOP/ $\mathrm{Rh}$ molar ratio of $5\left[50 \mathrm{mg}\right.$ of DIOP $+5 \mathrm{mg}$ of $\left.\left.\mathrm{Rh}(\mathrm{CO})_{2}(\mathrm{acac})\right]\right)$ by $\mathrm{CO}_{2}$ at $60{ }^{\circ} \mathrm{C}$. Initial volumes: $(\bullet) 5 \mathrm{~mL}$ and $(\mathrm{O}) 10 \mathrm{~mL}$.

Given that the catalyst concentration is small and toluene is the dominant component, the expansion ratios were almost identical for the different starting volumes of the mixtures ( 5 and $10 \mathrm{~mL}$ ). Further, the volumetric expansion is slightly higher for the $20 \mathrm{wt} \% 1,3$-butadiene reaction mixture compared to the $10 \mathrm{wt} \% 1,3$-butadiene mixture (Figure 3). This implies that the mixture containing more 1,3-butadiene (up to $20 \mathrm{wt} \%$ ) may be expanded to a greater extent than neat toluene. By visual observation, no precipitation of the $\mathrm{Rh} /$ DIOP complex was observed confirming that the catalyst remains dissolved in the $\mathrm{CO}_{2}$-expanded phase (essential for investigating homogeneous hydroformylation) at the conditions studied.

Volumetric expansion studies were also performed for pent4-enal + toluene hydroformylation mixtures containing the dissolved catalyst complex (Rh/DIOP) at $60{ }^{\circ} \mathrm{C}$ and pressures up to 60 bar. As seen from Figure 5, the volume of the liquid phase mixture increases with $\mathrm{CO}_{2}$ pressurization. The measured expansion ratios were almost similar to those

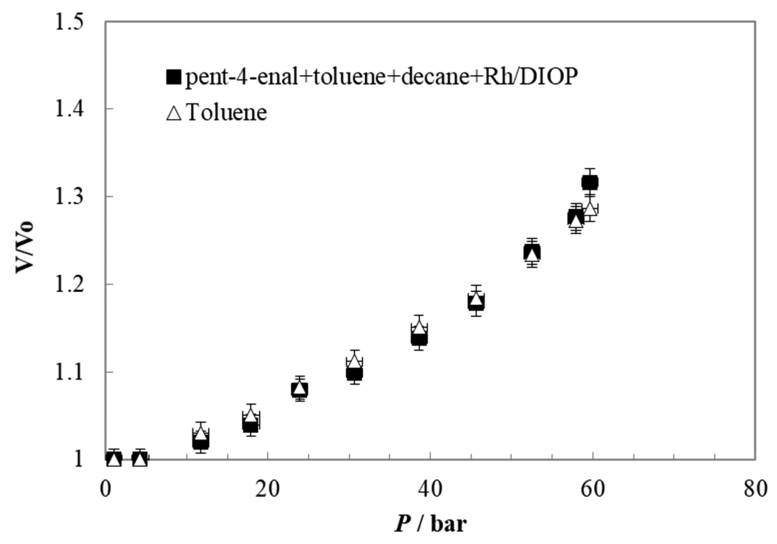

Figure 5. Volumetric expansion of pent-4-enal hydroformylation reaction mixture $(5 \mathrm{wt} \%$ pent-4-enal $+90 \mathrm{wt} \%$ toluene $+5 \mathrm{wt} \%$ decane $+\mathrm{DIOP} / \mathrm{Rh}$ molar ratio of $2.5[50 \mathrm{mg}$ of DIOP $+10 \mathrm{mg}$ of $\left.\left.\mathrm{Rh}(\mathrm{CO})_{2}(\mathrm{acac})\right]\right)$ by $\mathrm{CO}_{2}$ at $60{ }^{\circ} \mathrm{C}$. Initial volume: $10 \mathrm{~mL}$.

found for pure toluene. This is to be expected considering the relatively low concentration ( 5 wt \%) of pent-4-enal in the mixture. Further, the Rh/TPP catalyst complex remains dissolved in the toluene-based solution at the investigated $T$ and $P$ ranges. ${ }^{20,25}$

Simulations of the volumetric expansions were performed using ASPEN PLUS software employing the Peng-Robinson equation of state. ${ }^{27}$ As inferred from Figure 3, good agreement was observed between the experimental and simulated data for all mixtures. $^{29}$

Hydroformylation Experiments. Hydroformylation of 1,3-butadiene by the $\mathrm{Rh} / \mathrm{DIOP}$ catalyst complex was investigated in $\mathrm{CO}_{2}$-expanded solvent media. The reaction was first performed in neat toluene at $80{ }^{\circ} \mathrm{C}$ to benchmark literature results. Each experimental run shown in Table 1 was carried out at least twice to demonstrate reproducibility of the experimental procedure. Uncertainties in 1,3-butadiene conversion and aldehyde selectivities were estimated by calculating the standard deviations in measured values from several repeated runs under identical conditions. In addition, the $\mathrm{C}$ balance based on the $\mathrm{C}$ content in the feed (via $\mathrm{CO}$ consumed and the initial substrate concentration) and the $\mathrm{C}$ content in the liquid phase products match within experimental error. Detailed $\mathrm{C}$ balance calculations for all the runs are summarized in the Supporting Information (Tables S1-S3).

Table 1 summarizes the results of six benchmarking runs for 1,3-butadiene hydroformylation in neat toluene, varying parameters such as syngas partial pressure, temperature, and ligand/Rh ratio. The syngas consumption profiles corresponding to the runs in Table 1 are given in the Supporting Information (Figure S2). The results are generally in agreement with those reported in earlier studies. Ohgomori et $\mathrm{al}^{7}$ report that pent-3-enal selectivity varies between $53 \%-$ $67 \%$ and that the sum of pent-4-enal plus adipaldehyde selectivities varies between $33 \%-37 \%$. Results from the current work confirm that the selectivity toward pent-3-enal is dominant $(50 \%-62 \%)$ at all conditions studied and that the adipaldehyde selectivity ranges from $18 \%$ to $32 \%$. The $1,3-$ butadiene conversion (91\%) and the selectivity toward adipaldehyde (entry 2, Table 1) are close to those reported by Ohgomori et al. in neat toluene at similar values of temperature and syngas partial pressure. It is also seen that lower syngas partial pressures decrease both 1,3-butadiene conversion and adipaldehyde selectivity. At 20 bar syngas 
Table 1. Results of 1,3-Butadiene Hydroformylation with $\mathrm{Rh} / \mathrm{DIOP}$ Catalyst Complex in Toluene Medium at $80{ }^{\circ} \mathrm{C}^{a}$

\begin{tabular}{|c|c|c|c|c|c|c|c|c|c|c|}
\hline \multirow[b]{2}{*}{ entry } & \multicolumn{2}{|c|}{ Pressure (bar) } & \multirow[b]{2}{*}{$\mathrm{X}^{e}(\%)$} & \multicolumn{5}{|c|}{ Selectivity (\%) } & \multirow[b]{2}{*}{$n / i$} & \multirow[b]{2}{*}{ TOF $\left(h^{-1}\right)$} \\
\hline & $\mathrm{H}_{2} / \mathrm{CO}(1: 1)$ & $\mathrm{CO}_{2}$ & & Pent-3-enal & Pent-4-enal & Adipaldehyde & 2-Methylpentanedial & Pentanal & & \\
\hline 1 & 20 & - & 86 & 51 & 12 & 25 & - & 12 & - & 215 \\
\hline $2^{b}$ & 20 & - & 91 & 49 & 3 & 32 & - & 16 & - & 168 \\
\hline 3 & 10 & - & 60 & 53 & 21 & 18 & - & 16 & - & 151 \\
\hline 4 & 5 & - & 10 & 49 & 51 & - & - & - & - & $62^{d}$ \\
\hline $5^{c}$ & 20 & - & 93 & 25 & 4 & 28 & 22 & 20 & 1.3 & 240 \\
\hline $6^{c}$ & 10 & - & 76 & 62 & 10 & 22 & - & 5 & - & 223 \\
\hline 7 & 20 & 30 & 95 & 51 & - & 31 & 10 & 7 & 3.1 & 254 \\
\hline
\end{tabular}

${ }^{a}$ Reaction conditions: $30 \mathrm{mmol}$ of 1,3-butadiene; liquid phase volume, $10 \mathrm{~mL}$; reaction time, $4 \mathrm{~h}$; molar ratio DIOP/Rh= 5 [0.1 mmol DIOP, 0.02 $\left.\mathrm{mmol} \mathrm{Rh}(\mathrm{CO})_{2}(\mathrm{acac})\right] ; 1000 \mathrm{rpm} .{ }^{b}$ Reaction time: $8 \mathrm{~h} .{ }^{c} \mathrm{DIOP} / \mathrm{Rh}=2.5 .{ }^{d}$ TOF for entry 4 was calculated at $10 \%$ syngas conversion. ${ }^{e} \mathrm{X}: 1,3-$ butadiene conversion.

Table 2. Results of Pent-4-enal Hydroformylation with Rh/DIOP Catalyst Complex in Neat Toluene and $\mathrm{CO}_{2}$-Expanded Solvent $^{a}$

\begin{tabular}{|c|c|c|c|c|c|c|c|c|}
\hline \multirow[b]{2}{*}{ entry } & \multirow[b]{2}{*}{$\mathrm{T}\left({ }^{\circ} \mathrm{C}\right)$} & \multicolumn{2}{|c|}{ Pressure (bar) } & \multicolumn{3}{|c|}{ Selectivity (\%) } & \multirow[b]{2}{*}{$n / i$} & \multirow[b]{2}{*}{ TOF $\left(h^{-1}\right)$} \\
\hline & & $\mathrm{H}_{2} / \mathrm{CO}(1: 1)$ & $\mathrm{CO}_{2}$ & Adipaldehyde & 2-Methylpentanedial & Pentanal & & \\
\hline $1^{b}$ & 40 & 10 & - & 80 & 20 & - & 4 & 15 \\
\hline $2^{b, c}$ & 60 & 10 & - & 73 & 27 & - & 2.7 & 94 \\
\hline 3 & 60 & 10 & - & 72 & 28 & - & 2.6 & 126 \\
\hline 4 & 60 & 20 & - & 67 & 33 & - & 2 & 163 \\
\hline 5 & 80 & 10 & - & 69 & 24 & 7 & 2.9 & 334 \\
\hline 6 & 80 & 20 & - & 60 & 33 & 6 & 1.8 & 440 \\
\hline 7 & 80 & 50 & - & 61 & 36 & 4 & 1.7 & 466 \\
\hline 8 & 60 & 10 & 50 & 80 & 20 & - & 4 & 166 \\
\hline 9 & 80 & 10 & 50 & 75 & 14 & 11 & 5.3 & 344 \\
\hline
\end{tabular}

${ }^{a}$ Reaction conditions: $6 \mathrm{mmol}$ of pent-4-enal; liquid phase volume, $10 \mathrm{~mL}$; reaction time, $2 \mathrm{~h}$; molar DIOP/Rh $=2.5[0.1 \mathrm{mmol} \mathrm{DIOP}, 0.04 \mathrm{mmol}$ $\left.\mathrm{Rh}(\mathrm{CO})_{2}(\mathrm{acac})\right]$; $1000 \mathrm{rpm} .{ }^{b}$ Conversion of pent-4-enal is approximately $100 \%$ in all runs except for entry $1(<20 \%)$ and entry $2(<90 \%) .{ }^{c} \mathrm{Molar}$ ratio of $\mathrm{DIOP} / \mathrm{Rh}=5$.
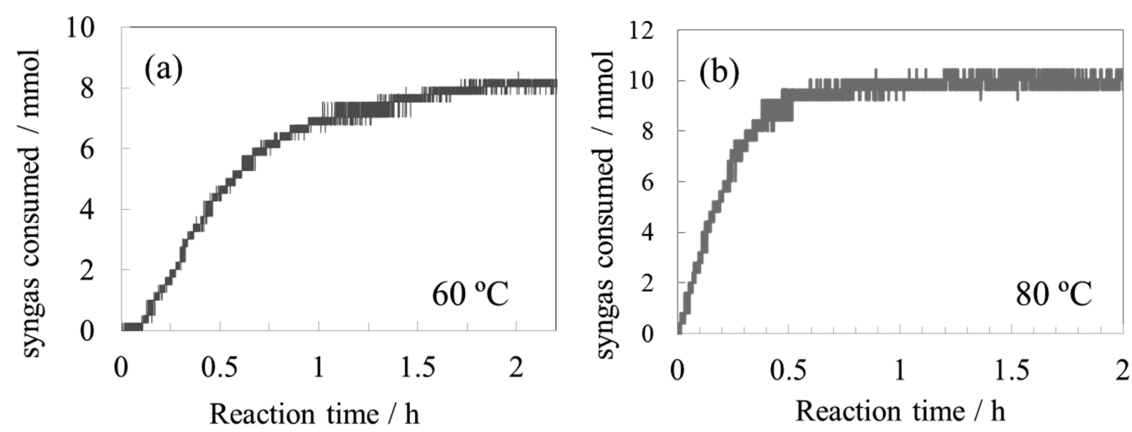

Figure 6. Syngas consumption profiles of pent-4-enal hydroformylation with Rh/DIOP catalyst complex at 10 bar syngas pressure and (a) $60{ }^{\circ} \mathrm{C}$ and (b) $80^{\circ} \mathrm{C}$.

pressure, the 1,3-butadiene conversion reaches $86 \%$ with an adipaldehyde selectivity of $25 \%$ (entry 1 , Table 1 ). However, at a syngas partial pressure of 5 bar, the 1,3-butadiene conversion is $10 \%$ with no measurable adipaldehyde formation (entry 4, Table 1 ). At 10 bar syngas pressure (entry 3 , Table 1 ), the 1,3butadiene conversion and adipaldehyde selectivity $(60 \%$ and $18 \%$, respectively) are intermediate to those observed at 5 and 20 bar syngas pressure. The corresponding TOFs are $215 \mathrm{~h}^{-1}$ at 20 bar syngas pressure and $62 \mathrm{~h}^{-1}$ at 5 bar syngas pressure. Lower ligand/Rh ratios favor 1,3-butadiene conversion and adipaldehyde selectivity (entries 5 and 6, Table 1). Also, the branched dialdehyde (2-methylpentanedial) is observed only at the lower molar ligand/ $\mathrm{Rh}$ ratio (2.6), with a $n / i$ ratio of $\sim 1.3$. A markedly higher $n / i$ ratio $(\sim 3.1)$ is obtained when the hydroformylation is performed in $\mathrm{CO}_{2}$-expanded toluene at 80 ${ }^{\circ} \mathrm{C}, 20$ bar syngas pressure, and 30 bar $\mathrm{CO}_{2}$ partial pressure (entry 7, Table 1). However, the adipaldehyde selectivity $(31 \%)$ is still quite low.

What is not clear from neither Table 1 results nor the literature are the effects of operating conditions on the relative rates of isomerization between pent-3-enal and pent-4-enal, and of the secondary hydroformylation steps involving these two species. The increased selectivity toward adipaldehyde (Table 1 and Scheme 1) confirms that the hydroformylation of the terminal aldehyde (pent-4-enal) to produce adipaldehyde proceeds much faster relative to that of the internal aldehyde (pent-3-enal). This raises the question of whether there are operating conditions that would further enhance the secondary hydroformylation of pent-4-enal toward adipaldehyde and thereby also shift the isomerization equilibrium toward pent-4enal. 

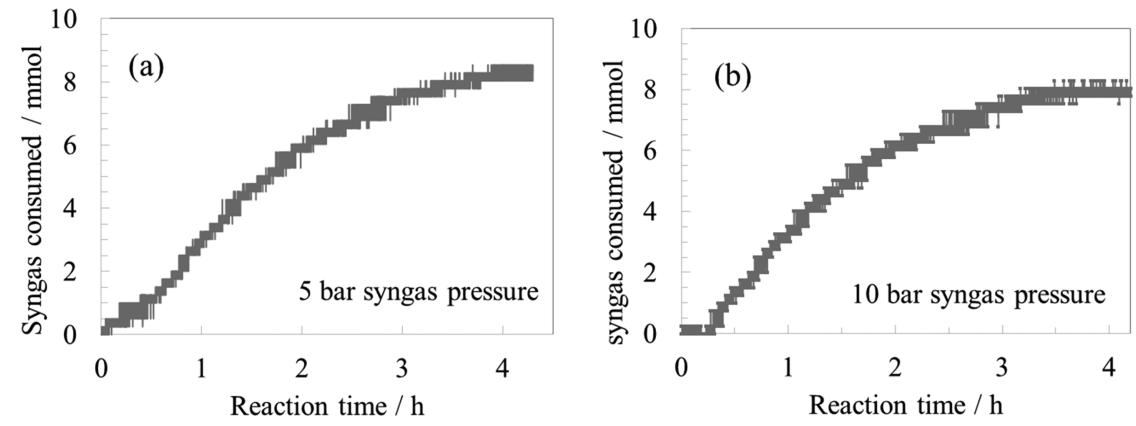

Figure 7. Syngas consumption profiles of pent-4-enal hydroformylation with Rh/TPP catalyst complex at $60{ }^{\circ} \mathrm{C}$ and syngas partial pressure of (a) 5 bar and (b) 10 bar.

Table 3. Results of Pent-4-enal Hydroformylation with Rh/TPP Catalyst Complex in Neat Toluene and $\mathrm{CO}_{2}$-Expanded Reaction Medium at $60^{\circ} \mathrm{C}^{a}$

\begin{tabular}{|c|c|c|c|c|c|c|}
\hline \multirow[b]{2}{*}{ entry } & \multicolumn{2}{|c|}{ Pressure (bar) } & \multicolumn{2}{|c|}{ Selectivity (\%) } & \multirow[b]{2}{*}{$n / i$} & \multirow[b]{2}{*}{ TOF $\left(h^{-1}\right)$} \\
\hline & $\mathrm{H}_{2} / \mathrm{CO}(1: 1)$ & $\mathrm{CO}_{2}$ & Adipaldehyde & 2-Methylpentanedial & & \\
\hline $1^{b}$ & 5 & - & 67 & 19 & 3.5 & 48 \\
\hline 2 & 10 & - & 71 & 29 & 2.5 & 61 \\
\hline $3^{b}$ & 5 & 30 & 61 & 14 & 4.3 & 72 \\
\hline $4^{b}$ & 5 & 50 & 70 & 14 & 4.8 & 78 \\
\hline 5 & 10 & 30 & 81 & 19 & 4.2 & 83 \\
\hline 6 & 10 & 50 & 85 & 15 & 5.6 & 85 \\
\hline
\end{tabular}

${ }^{a}$ Reaction conditions: $6 \mathrm{mmol}$ of pent-4-enal; liquid phase volume, $10 \mathrm{~mL}$; reaction time, $4 \mathrm{~h}$; molar TPP/Rh $=120[4.8 \mathrm{mmol} \mathrm{TPP}, 0.04 \mathrm{mmol}$ $\left.\mathrm{Rh}(\mathrm{CO})_{2}(\mathrm{acac})\right] ; 1000 \mathrm{rpm} .{ }^{b}$ Remaining products are undesired and not identified.

We investigated the hydroformylation of pent-4-enal on both $\mathrm{Rh} / \mathrm{DIOP}$ and $\mathrm{Rh} / \mathrm{TPP}$ catalyst complexes in neat toluene and $\mathrm{CO}_{2}$-expanded reaction media. As inferred from Table 2 and Figure 6, the reaction is nearly complete in all cases, except at $40{ }^{\circ} \mathrm{C}$, where the pent-4-enal conversion reaches less than $20 \%$. The reaction is significantly faster at 80 ${ }^{\circ} \mathrm{C}$, reaching nearly total conversions in less than $1 \mathrm{~h}$ (Figure 6b). Additional syngas consumption profiles for the various runs in Table 2 are included in the Supporting Information (Figure S3).

At a given temperature, adipaldehyde selectivity is generally favored at lower syngas pressure (entries 3 and 4, entries 5 and 6, Table 2). At a constant syngas pressure, the end-of-run adipaldehyde selectivity is generally higher at lower temperature (entries 3 and 5, entries 4 and 6, Table 2). Higher temperatures $\left(80^{\circ} \mathrm{C}\right.$ ) lead to the formation pentanal (entries 5-7 and 9) that adversely affects the chemoselectivity. Doubling the ligand/Rh molar ratio from 2.5 to 5 decreases TOF from 126 to $94 \mathrm{~h}^{-1}$ but has minimal effect on the regioselectivity (entries 2 and 3, Table 2).

The hydroformylation of pent-4-enal with the Rh/TPP catalyst is much slower than with $\mathrm{Rh} / \mathrm{DIOP}$ catalysts, reaching complete conversion a greater than $3 \mathrm{~h}$ at similar operating conditions (Figure 7). The regioselectivity values (entries 1 and 2, Table 3) are comparable to that obtained with $\mathrm{Rh} /$ DIOP in neat toluene at $60{ }^{\circ} \mathrm{C}$ (entry 3, Table 2). However, the adipaldehyde selectivity of $60 \%$ (entry 6 , Table 2 ) is less than the value $(91 \%)$ reported by Mormul et al. ${ }^{12}$

Guided by the foregoing results that show higher adipaldehyde selectivity at low syngas pressure (10 bar) at 60 and $80^{\circ} \mathrm{C}$ (entries 3 and 5, Table 2), the effects of 50 bar $\mathrm{CO}_{2}$ addition on TOF and product selectivity were investigated. With $\mathrm{CO}_{2}$ addition, the TOF and regioselectivity at $60{ }^{\circ} \mathrm{C}$ are increased to $166 \mathrm{~h}^{-1}$ and 4.0 (entry 8, Table 2) compared to $126 \mathrm{~h}^{-1}$ and 2.6 without $\mathrm{CO}_{2}$ addition (entry 3, Table 2). It must be noted that the initial volumes of the reaction mixture (toluene-based and CXL), and hence the initial concentrations of the substrate and catalyst in the liquid phase, are identical in these two cases. Increasing the temperature to $80{ }^{\circ} \mathrm{C}$ enhances the TOF $\left(344 \mathrm{~h}^{-1}\right)$, adipaldehyde selectivity (75\%), and regioselectivity (5.3) but also forms pentanal, the hydrogenated product (entry 9, Table 2).

We also investigated pent-4-enal hydroformylation with $\mathrm{Rh} /$ TPP, a simple $\mathrm{Rh}$ complex, in $\mathrm{CO}_{2}$-expanded toluene medium, while maintaining the same initial volume and concentrations in both cases. At similar syngas partial pressures and temperature, both the TOF and regioselectivity increase in CXL media (Table 3). Further, Rh/TPP provides better adipaldehyde selectivity than Rh/DIOP in a CXL medium. With 50 bar $\mathrm{CO}_{2}$ pressure, the observed adipaldehyde selectivity and regioselectivity with the $\mathrm{Rh} / \mathrm{TPP}$ complex are $85 \%$ and 5.5, respectively, with a TOF of $85 \mathrm{~h}^{-1}$ (entry 6, Table 3). At similar conditions, adipaldehyde selectivity and regioselectivity observed with the Rh/DIOP catalyst in a CXL medium are $80 \%$ and 4 , respectively (entry 8 , Table 2 ). This demonstrates the ability of CXL media to tune regioselectivity at a relatively mild temperature and pressure, without the use of exotic ligands.

The foregoing results demonstrate that CXL media enhance TOF and regioselectivity during pent-4-enal hydroformylation. Although $\mathrm{H}_{2} / \mathrm{CO}$ ratios in conventional liquid phase reaction media are less compared to the feed syngas, they can be pressure-tuned in CXLs to achieve greater $\mathrm{H}_{2} / \mathrm{CO}$ ratios. ${ }^{18,29}$ Yin and $\operatorname{Tan}^{30}$ reported VLE of binary and ternary systems involving $\mathrm{CO}_{2}, \mathrm{H}_{2}$, and toluene between 32 to $70{ }^{\circ} \mathrm{C}$ and pressures up to 105 bar. Professor Eckert's group reported on the VLE of $\mathrm{CO}_{2}+$ methanol $+\mathrm{H}_{2}$ at $40{ }^{\circ} \mathrm{C} .{ }^{31}$ In both studies, 
the $\mathrm{H}_{2}$ solubility in the liquid phase is greater in the presence of $\mathrm{CO}_{2}$ than without $\mathrm{CO}_{2}$. In another study, ${ }^{32}$ the Eckert group reported enhanced turnover frequency of a water-soluble catalyst system for the hydroformylation of 1-octene, using $\mathrm{CO}_{2}$ used as a miscibility switch for efficient product and catalyst recovery. Lopez-Castillo et al. ${ }^{17}$ reported that $\mathrm{H}_{2}$ solubility in $\mathrm{CO}_{2}$-expanded liquids is greater than without $\mathrm{CO}_{2}$ at identical $\mathrm{H}_{2}$ fugacities in the case of the $\mathrm{CO}_{2} / \mathrm{H}_{2}$ / methanol, $\mathrm{CO}_{2} / \mathrm{H}_{2}$ /acetonitrile, and $\mathrm{CO}_{2} / \mathrm{H}_{2}$ /acetone ternary systems at $40{ }^{\circ} \mathrm{C}$ up to $90 \mathrm{bar}$. Although the solubility of $\mathrm{CO}$ in the $\mathrm{CO}_{2} / \mathrm{CO} /$ methanol, $\mathrm{CO}_{2} / \mathrm{CO} /$ acetonitrile, and $\mathrm{CO}_{2} /$ $\mathrm{CO} /$ acetone ternary systems is also greater with $\mathrm{CO}_{2}$ addition (i.e., in CXL media), this increase is relatively modest at the investigated conditions $\left(25-40{ }^{\circ} \mathrm{C}\right.$ and pressures up to 90 bar). ${ }^{16}$ Zevnik and Levec reported solubility of $\mathrm{H}_{2}$ in $\mathrm{CO}_{2}$ expanded 2-propanol at 25 and $40{ }^{\circ} \mathrm{C}$ and pressures between 60 and 120 bar. Their data also show that hydrogen concentration increases with $\mathrm{CO}_{2}$ expansion of the 2-propanol phase. ${ }^{19}$ Thus, there is compelling literature evidence that the solubilities of $\mathrm{CO}$ and $\mathrm{H}_{2}$ are enhanced in both polar and nonpolar solvents expanded by $\mathrm{CO}_{2}$. Thus, the tunability of $\mathrm{CO}$ and $\mathrm{H}_{2}$ solubilities in the CXL phase with a syngas feed to constant composition leads to beneficial effects on TOF, chemoselectivity, and regioselectivity during pent-4-enal hydroformylation over $\mathrm{Rh} / \mathrm{DIOP}$ and $\mathrm{Rh} / \mathrm{TPP}$ catalyst complexes.

\section{CONCLUSIONS}

The influence of syngas partial pressure, temperature, ligand/ $\mathrm{Rh}$ ratio, and CXL media on 1,3-butadiene and pent-4-enal hydroformylation using $\mathrm{Rh} / \mathrm{DIOP}$ and $\mathrm{Rh} / \mathrm{TPP}$ complexes was systematically investigated. For 1,3-butadiene hydroformylation, pent-3-enal is the favored product at all investigated conditions, resulting in a relatively low adipaldehyde selectivity. In contrast, pent-4-enal hydroformylation is facile with both ligands, and especially so in CXL media providing enhanced TOF $\left(344 \mathrm{~h}^{-1}\right.$ ) and regioselectivity (5.3) toward adipaldehyde, even with $\mathrm{Rh} / \mathrm{TPP}$ ligand, at relatively mild conditions ( 10 bar syngas, 50 bar $\mathrm{CO}_{2}$, and $60{ }^{\circ} \mathrm{C}$ ). This approach to accelerate pent-4-enal hydroformylation to form adipaldehyde should help in overcoming equilibrium limitations typically associated with the catalytic isomerization of pent-3-enal (the dominant product from 1,3 butadiene hydroformylation) to pent-4-enal (the preferred isomer). In other words, during 1,3-butadiene hydroformylation, combining an active isomerization catalyst that converts pent-3-enal to pent-4-enal with the use of CXL media to accelerate adipaldehyde formation (from pent-4-enal) could significantly enhance the selectivity toward adipaldehyde.

\section{TRIBUTE TO PROFESSOR CHUCK ECKERT}

This work on $\mathrm{CO}_{2}$-expanded liquids relied on learnings from the pioneering work of Professor Eckert's group in the field of gas-expanded liquids. In lieu of a champagne $\left(\mathrm{a} \mathrm{CO}_{2}\right.$-expanded liquid itself!) toast to Professor Eckert's good health on his birthday, we hope that this contribution is a fitting tribute to his outstanding contributions to the field of chemical engineering. It is a distinct privilege and pleasure to have known Chuck and to be invited to contribute to this special issue honoring him.

\section{ASSOCIATED CONTENT}

\section{Supporting Information}

The Supporting Information is available free of charge on the ACS Publications website at DOI: 10.1021/acs.iecr.9b05184.

Typical GC/FID chromatogram of 1,3-butadiene hydroformylation products, $\mathrm{C}$ balance calculations, and syngas consumption profiles for the runs in Tables $1-3$. (PDF)

\section{AUTHOR INFORMATION}

\section{Corresponding Author}

*E-mail: bsubramaniam@ku.edu. Tel.: +1-785-864-2903. Fax: +1-785-864-6051.

ORCID $\odot$

Raghunath V. Chaudhari: 0000-0002-1972-1620

Bala Subramaniam: 0000-0001-5361-1954

Notes

The authors declare no competing financial interest.

\section{ACKNOWLEDGMENTS}

The authors gratefully acknowledge support for this work by a grant from the joint National Science Foundation and Environmental Protection Agency program Networks for Sustainable Material Synthesis and Design program (NSFEPA 1339661).

\section{REFERENCES}

(1) Carothers, W. H. Linear polyamides and their production. U.S. Patent 2130523 A, 1938

(2) Carothers, W. H. Synthetic fiber. U.S. Patent 2130948 A, 1938.

(3) Seidel, A.; Kirk, R. E.; Othmer, D. F.; Kroschwitz, J. I.; HoweGrant, M. Kirk-Othmer Encyclopedia of Chemical Technology; Wiley, 2007.

(4) Adkins, H.; Williams, J. R. Hydroformylation of conjugated dienes. J. Org. Chem. 1952, 17, 980.

(5) Huo, C. F.; Li, Y. W.; Beller, M.; Jiao, H. J. Regioselective hydroformylation of butadiene: Density functional studies. Organometallics 2005, 24, 3634-3643.

(6) Packett, D. L.; Briggs, J. R.; Bryant, D. R.; Phillips, A. G. Processes for producing 1,6-hexanedials and derivatives. U.S. Patent 5892127 A, 1999.

(7) Ohgomori, Y.; Suzuki, N.; Sumitani, N. Formation of 1,6hexanedial via hydroformylation of 1,3-butadiene. J. Mol. Catal. A: Chem. 1998, 133, 289-291.

(8) Smith, S. E.; Rosendahl, T.; Hofmann, P. Toward the rhodiumcatalyzed bis-hydroformylation of 1,3-butadiene to adipic aldehyde. Organometallics 2011, 30, 3643-3651.

(9) Teunissen, A. J. J. M.; de Vries, J. G.; Gelling, O. J.; Lensink, C. Process for the preparation of a linear aldehyde organic compound. U.S. Patent 5811589 A, 1998.

(10) Janssen, M. C. C.; Sereinig, N.; Van, D. V. E. W. M.; Vries, D. J. G. Process to produce adipic acid and diesters thereof in a carbonylation process using palladium bidentate biphosphate ligands. WO Patent 2012131028 A1, 2012.

(11) Rosendahl, T. Synthese und Komplexierungsverhalten neuer modularer Chelatphosphitliganden sowie ihre Anwendung in der Rhodium-katalysierten Hydroformylierung. Dissertation, University of Heidelberg, 2007.

(12) Mormul, J.; Mulzer, M.; Rosendahl, T.; Rominger, F.; Limbach, M.; Hofmann, P. Synthesis of adipic aldehyde by n-selective hydroformylation of 4-pentenal. Organometallics 2015, 34, 41024108.

(13) Jessop, P. G.; Subramaniam, B. Gas-expanded liquids. Chem. Rev. 2007, 107, 2666-2694. 
(14) Akien, G. R.; Poliakoff, M. A critical look at reactions in class I and II gas-expanded liquids using $\mathrm{CO} 2$ and other gases. Green Chem. 2009, 11, 1083-1100.

(15) Leitner, W.; Jessop, P. G. Handbook of Green Chemistry - Green Solvents; Wiley, 2013; Vol. 3.

(16) Lopez-Castillo, Z. K.; Aki, S. N. V. K.; Stadtherr, M. A.; Brennecke, J. F. Enhanced solubility of oxygen and carbon monoxide in $\mathrm{CO}_{2}$-expanded liquids. Ind. Eng. Chem. Res. 2006, 45, 5351-5360.

(17) Lopez-Castillo, Z. K.; Aki, S. N. V. K.; Stadtherr, M. A.; Brennecke, J. F. Enhanced solubility of hydrogen in $\mathrm{CO}_{2}$-expanded liquids. Ind. Eng. Chem. Res. 2008, 47, 570-576.

(18) Xie, Z.; Snavely, W. K.; Scurto, A. M.; Subramaniam, B. Solubilities of $\mathrm{CO}$ and $\mathrm{H}_{2}$ in neat and $\mathrm{CO}_{2}$-expanded hydroformylation reaction mixtures containing 1-octene and nonanal up to 353.15 K and 9 MPa. J. Chem. Eng. Data 2009, 54, 1633-1642.

(19) Zevnik, L.; Levec, J. Hydrogen solubility in $\mathrm{CO}_{2}$-expanded 2propanol and in propane-expanded 2-propanol determined by an acoustic sensor. J. Supercrit. Fluids 2007, 41, 335-342.

(20) Jin, H.; Subramaniam, B.; Ghosh, A.; Tunge, J. Intensification of catalytic olefin hydroformylation in $\mathrm{CO}_{2}$-expanded media. AIChE J. 2006, 52, 2575-2581.

(21) Bhanage, B. M.; Divekar, S. S.; Deshpande, R. M.; Chaudhari, R. V. Kinetics of hydroformylation of 1-dodecene using homogeneous $\mathrm{HRh}(\mathrm{CO})\left(\mathrm{PPh}_{3}\right)_{3}$ catalyst. J. Mol. Catal. A: Chem. 1997, 115, 247257.

(22) Luehring, P.; Schumpe, A. Gas solubilities (hydrogen, helium, nitrogen, carbon monoxide, oxygen, argon, carbon dioxide) in organic liquids at 293.2 K. J. Chem. Eng. Data 1989, 34, 250-252.

(23) Jáuregui-Haza, U. J.; Pardillo-Fontdevila, E. J.; Wilhelm, A. M.; Delmas, $\mathrm{H}$. Solubility of hydrogen and carbon monoxide in water and some organic solvents. Lat. Am. Appl. Res. 2004, 34, 71-74.

(24) Purwanto; Deshpande, R. M.; Chaudhari, R. V.; Delmas, H. Solubility of hydrogen, carbon monoxide, and 1-octene in various solvents and solvent mixtures. J. Chem. Eng. Data 1996, 41, 14141417.

(25) Xie, Z.; Fang, J.; Subramaniam, B.; Maiti, S. K.; Snavely, W.; Tunge, J. A. Enhanced hydroformylation by carbon dioxide-expanded media with soluble $\mathrm{Rh}$ complexes in nanofiltration membrane reactors. AIChE J. 2013, 59, 4287-4296.

(26) Jin, H.; Subramaniam, B. Homogeneous catalytic hydroformylation of 1-octene in $\mathrm{CO}_{2}$-expanded solvent media. Chem. Eng. Sci. 2004, 59, 4887-4893.

(27) Peng, D.-Y.; Robinson, D. B. A new two-constant equation of state. Ind. Eng. Chem. Fundam. 1976, 15, 59-64.

(28) Guha, D.; Jin, H.; Dudukovic, M. P.; Ramachandran, P. A.; Subramaniam, B. Mass transfer effects during homogeneous 1-octene hydroformylation in $\mathrm{CO}_{2}$-expanded solvent: modeling and experiments. Chem. Eng. Sci. 2007, 62, 4967-4975.

(29) Ye, K.; Freund, H.; Xie, Z.; Subramaniam, B.; Sundmacher, K. Prediction of multicomponent phase behavior of $\mathrm{CO}_{2}$-expanded liquids using $\mathrm{CEoS} / \mathrm{GE}$ models and comparison with experimental data. J. Supercrit. Fluids 2012, 67, 41-52.

(30) Yin, J.-Z.; Tan, C.-S. Solubility of hydrogen in toluene for the ternary system $\mathrm{H}_{2}+\mathrm{CO}_{2}+$ toluene from 305 to $343 \mathrm{~K}$ and 1.2 to 10.5 MPa. Fluid Phase Equilib. 2006, 242, 111-117.

(31) Xie, X.; Brown, J. S.; Bush, D.; Eckert, C. A. Bubble and Dew Point Measurements of the Ternary System Carbon Dioxide + Methanol + Hydrogen at 313.2 K. J. Chem. Eng. Data 2005, 50, 780783.

(32) Hallett, J. P.; Ford, J. W.; Jones, R. S.; Pollet, P.; Thomas, C. A.; Liotta, C. L.; Eckert, C. A. Hydroformylation catalyst recycle with gasexpanded liquids. Ind. Eng. Chem. Res. 2008, 47, 2585-2589. 